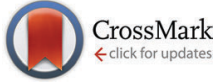

Cite this: J. Mater. Chem. C, 2015 3, 10898

Received 27th July 2015,

Accepted 16th September 2015

DOI: $10.1039 / c 5 t c 02293 b$

www.rsc.org/MaterialsC

\title{
Gas phase chemical vapor deposition chemistry of triethylboron probed by boron-carbon thin film deposition and quantum chemical calculations $\dagger$
}

\author{
Mewlude Imam, ${ }^{\mathrm{ab}}$ Konstantin Gaul, ${ }^{\mathrm{c}}$ Andreas Stegmüller, ${ }^{c}$ Carina Höglund, ${ }^{\text {ab }}$ \\ Jens Jensen, ${ }^{a}$ Lars Hultman, ${ }^{a}$ Jens Birch, ${ }^{a}$ Ralf Tonner ${ }^{\star c}$ and Henrik Pedersen*a
}

\begin{abstract}
We present triethylboron (TEB) as a single-source precursor for chemical vapor deposition (CVD) of $\mathrm{B}_{x} \mathrm{C}$ thin films and study its gas phase chemistry under CVD conditions by quantum chemical calculations. A comprehensive thermochemical catalogue for the species of the gas phase chemistry of TEB is examined and found to be dominated by $\beta$-hydride eliminations of $\mathrm{C}_{2} \mathrm{H}_{4}$ to yield $\mathrm{BH}_{3}$. A complementary bimolecular reaction path based on $\mathrm{H}_{2}$ assisted $\mathrm{C}_{2} \mathrm{H}_{6}$ elimination to $\mathrm{BH}_{3}$ is also significant at lower temperatures in the presence of hydrogen. Furthermore, we find a temperature window of $600-1000{ }^{\circ} \mathrm{C}$ for the deposition of $X$-ray amorphous $B_{x} C$ films with $2.5 \leq x \leq 4.5$ from TEB. Films grown at temperatures below $600{ }^{\circ} \mathrm{C}$ contain high amounts of $\mathrm{H}$, while temperatures above $1000{ }^{\circ} \mathrm{C}$ result in $\mathrm{C}$-rich films. The film density and hardness are determined to be in the range of $2.40-2.65 \mathrm{~g} \mathrm{~cm}^{-3}$ and 29-39 GPa, respectively, within the determined temperature window.
\end{abstract}

\section{Introduction}

Boron forms technically very interesting compounds including boron carbides $\left(\mathrm{B}_{4} \mathrm{C}\right)$. The rhombohedral phase of $\mathrm{B}_{4} \mathrm{C}$ is a very hard, light-weight material with high chemical and thermal stability as well as high wear resistance. ${ }^{1}$ Although it is nominally called $\mathrm{B}_{4} \mathrm{C}$, the carbon concentration of the compound can vary from 9 to 20 at\% and exist as a stable single phase in a large homogeneous region from $\mathrm{B}_{4} \mathrm{C}$ to $\mathrm{B}_{10.4} \mathrm{C}^{2,3}$ Boron nitride (BN) is isoelectronic to carbon and can form compounds with either $\mathrm{sp}^{3}$-hybridized or $\mathrm{sp}^{2}$-hybridized bonds. The most studied $\mathrm{sp}^{3}$-hybridized phase is the cubic (c-BN), which is isoelectronic to diamond, but there is also a wurtzite phase (w-BN), which is isostructural to Lonsdaleite (hexagonal diamond). The interest for c-BN mainly stems from the phase similarities to diamond: c-BN is regarded as the hardest material after diamond and developed as hard coatings for cutting tools. The $\mathrm{sp}^{2}$-hybridized $\mathrm{BN}$ can crystallize into two different phases: hexagonal (h-BN)

\footnotetext{
${ }^{a}$ Department of Physics, Chemistry, and Biology (IFM), Linköping University, SE-58183 Linköping, Sweden.E-mail:yimma@ifm.liu.se, henrik.pedersen@liu.se ${ }^{b}$ European Spallation Source ESS AB, P. O. Box 176, SE-22100, Lund, Sweden ${ }^{c}$ Fachbereich Chemie and Material Sciences Center, Philipps-Universität Marburg, Hans-Meerwein-Straße 4, D-35032 Marburg, Germany.

E-mail: tonner@chemie.uni-marburg.de

$\dagger$ Electronic supplementary information (ESI) available: Tables with more details of the atomic content and measured densities and hardness of the films, and more details of the computations together with Cartesian coordinates of structures. See DOI: 10.1039/c5tc02293b
}

and rhombohedral ( $\mathrm{r}-\mathrm{BN})$ are envisioned as promising materials for photonics and electronics. ${ }^{4}$ The hexagonal polytype is isostructural to graphite and can, like graphite, form a stable two-dimensional material. Single layers of h-BN are used in combination with graphene in the exploration of electronics based on two-dimensional materials. ${ }^{5}$ It is reported both theoretically and experimentally that h-BN has a direct band gap and is likely around $6 \mathrm{eV}$. ${ }^{4}$ Moreover, employing $\mathrm{Mg}$ as a p-type dopant for $\mathrm{sp}^{2}$-BN shows a lower activation energy of the $\mathrm{Mg}$ acceptor of $\sim 31 \mathrm{meV}$, this makes it more attractive for deep UV application than AlN. ${ }^{4}$ Except all the applications mentioned above, there is one emerging application for boron-based materials, both $\mathrm{B}_{4} \mathrm{C}^{6}$ and $\mathrm{BN}^{7}$ are promising neutron converting layers in new generation neutron detectors. The isotope ${ }^{10} \mathrm{~B}$, with $20 \%$ natural abundance, has a high absorption cross-section for thermal neutrons, and reacts in either of the reactions (1) and (2), when a neutron is captured:

94\%: ${ }^{10} \mathrm{~B}+\mathrm{n} \rightarrow{ }^{7} \mathrm{Li}(0.84 \mathrm{MeV})+{ }^{4} \mathrm{He}(1.47 \mathrm{MeV})+\gamma(0.48 \mathrm{MeV})$

$$
6 \%:{ }^{10} \mathrm{~B}+\mathrm{n} \rightarrow{ }^{7} \mathrm{Li}(1.02 \mathrm{MeV})+{ }^{4} \mathrm{He}(1.78 \mathrm{MeV})
$$

$\mathrm{A}{ }^{10} \mathrm{~B}$ based neutron detector uses these reactions to convert neutrons into detectable particles and has been hailed as a suitable alternative to ${ }^{3} \mathrm{He}$ based neutron detectors ${ }^{8}$ in the light of a very limited supply of ${ }^{3} \mathrm{He} .{ }^{9}$

Boron-based compounds are often used in the form of thin films with thicknesses from a single atomic layer to several micrometers. 
One of the routes to fabricate such films is chemical vapor deposition (CVD), which is a family of techniques where thin films are formed from chemical reactions between volatile molecules containing the atoms needed for the thin film. Volatile boron based molecules can be made by forming boron hydrides, typically diborane $\left(\mathrm{B}_{2} \mathrm{H}_{6}\right)$, boron halides, typically boron trichloride $\left(\mathrm{BCl}_{3}\right)$, and organoboranes, typically triethylboron $\left(\mathrm{B}\left(\mathrm{C}_{2} \mathrm{H}_{5}\right)_{3}\right)$. The boron hydrides are attractive CVD precursors as they apart from boron contain only hydrogen. This leads to a low risk of the incorporation of unwanted atoms into the films since hydrogen is often used as a carrier gas in CVD. The boron hydrides, especially $\mathrm{B}_{2} \mathrm{H}_{6}$, are however very toxic and explosive and therefore problematic to handle. The boron halides have been successfully used for CVD of boron carbides but require rather high process temperatures of $1000-1300{ }^{\circ} \mathrm{C} .{ }^{10}$ The boron halides, particularly $\mathrm{BCl}_{3}$, are not suited as precursors for $\mathrm{BN}$ as the $\mathrm{HCl}$ by-product will form solid $\mathrm{NH}_{4} \mathrm{Cl}$ together with the typical nitrogen precursor ammonia $\left(\mathrm{NH}_{3}\right)$ which may damage the vacuum pump of the CVD system. The hydrogenhalide by-products as a result of employing boron halides are also very corrosive and can badly affect metallic substrates used for CVD of single layer $\mathrm{BN}^{11}$ or as a basis for neutron detectors. ${ }^{6}$ Organoboranes are therefore an attractive class of precursor molecules for CVD of boron-based materials. The most common organoborane is $\mathrm{B}\left(\mathrm{C}_{2} \mathrm{H}_{5}\right)_{3}$, hereafter referred to as TEB. TEB has a melting point of $-92.8{ }^{\circ} \mathrm{C}$ and boils at $95{ }^{\circ} \mathrm{C} .{ }^{12}$ The vapor pressure $(P)$ in bar for TEB at a temperature $(T)$ in Kelvin is calculated using $\log (P)=2.91408-(753.261 /(T-112.631)) .{ }^{13}$ It has successfully been used for CVD of both boron-carbon $\left(\mathrm{B}_{x} \mathrm{C}\right)^{14}$ and $\mathrm{BN}^{15}$ thin films. Also trimethylboron $\left(\mathrm{B}\left(\mathrm{CH}_{3}\right)_{3}\right)$ and tributylboron $\left(\mathrm{B}\left(\mathrm{C}_{4} \mathrm{H}_{9}\right)_{3}\right)$ have been reported for CVD of boroncarbon thin films. ${ }^{16}$ The organoboranes are particularly interesting for boron carbides as they can function as both boron and carbon precursors.

For any material, a high level of understanding of the chemistry of the precursor molecules is of great importance when improving and developing CVD processes. The CVD chemistry of organoboranes has not been fully studied. The TEB molecule has been suggested to undergo $\beta$-hydride elimination in the gas phase at temperatures above $300{ }^{\circ} \mathrm{C},{ }^{16}$ which was used as a basis for a speculation around the CVD chemistry of BN CVD at $1500{ }^{\circ} \mathrm{C}^{15}$ A gas phase chemistry mechanism for TEB based on $\beta$-hydride elimination of $\mathrm{C}_{2} \mathrm{H}_{4}$ and $\mathrm{H}_{2}$ assisted elimination of $\mathrm{C}_{2} \mathrm{H}_{6}$ has been sketched to explain the film deposition of $\mathrm{B}_{x} \mathrm{C}$ films from TEB at 400-600 ${ }^{\circ} \mathrm{C}^{14}$ However, these attempts to explain the CVD chemistry are only based on the experimental results from deposited $\mathrm{B}_{x} \mathrm{C}$ and $\mathrm{BN}$ films.

In this paper, we aim to establish a comprehensive gas phase CVD chemistry for TEB. We use the ability of TEB to act as a single-source precursor for $\mathrm{B}_{x} \mathrm{C}$ films, allowing us to study the film deposition from using only TEB diluted in $\mathrm{H}_{2}$ or Ar. Any gas phase interactions with other precursor molecules are thus avoided. In addition to the film deposition, possible gas phase reactions, both within the TEB molecule (unimolecular) and between the TEB molecule and the $\mathrm{H}_{2}$ carrier gas (bimolecular), are studied by quantum chemical calculations. A gas phase chemical mechanism for TEB under CVD conditions is then suggested based on the combined experimental and quantum chemical results. The results presented here may be useful in the further understanding and development of CVD of boronbased materials.

\section{Methods}

\section{Film deposition}

A hot-wall CVD reactor equipped with an inductively heated, SiC-coated graphite susceptor was used for the deposition of $\mathrm{B}_{x} \mathrm{C}$ films from TEB. Further details of this type of CVD reactor are described in ref. 17. As a carrier gas, palladium membranepurified $\mathrm{H}_{2}$ or $\mathrm{Ar}$ (99.9997\%) was used. The process pressure was controlled by a throttle valve and set to $50 \mathrm{mbar}$. The TEB from SAFC Hitch was of semiconductor grade purity and kept in a stainless steel bubbler immersed in a temperature-controlled water/glycol bath to ensure a constant, well-controlled temperature of $7{ }^{\circ} \mathrm{C}$, which gives a TEB vapor pressure of $28.7 \mathrm{mbar}$. A small flow of the carrier gas, controlled by an electronic mass flow controller, was bubbled through the liquid TEB. The pressure in the bubbler was set by an electronic pressure controller. The TEB concentration in the gas mixture in the reactor was $0.06 \%$, as determined by taking the ratio of TEB flow to the total gas flow in the chamber. Single-crystal, (100)-oriented Si wafers were used as substrates for the deposition. Prior to deposition, the substrates were ultrasonically cleaned with acetone and isopropanol, and dried with dry $\mathrm{N}_{2}$.

\section{Film characterization}

The film thickness, used to calculate the deposition rate, was determined by cross-sectional scanning electron microscopy (SEM) on cleaved samples using a LEO 1550 Gemini SEM equipped with a field emission gun (FEG). Time-of-flight elastic recoil detection analysis (ToF-ERDA), a technique that provides relative amounts of all included elements, was used to determine elemental composition of films using $36 \mathrm{MeV}$ iodine ions. The experimental details of the ToF-ERDA can be found elsewhere. ${ }^{18,19}$ Film crystallinity was studied by XRD in a Bragg-Brentano configuration within the $20-80^{\circ}$ scanning range using $\mathrm{Cu}-\mathrm{K}_{\alpha}$ radiation. $\mathrm{X}$-ray reflectivity (XRR) has been carried out on samples using a Philips X'Pert Pro MRD diffractometer equipped with a hybrid mirror monochromator and a 2-bounce Ge 220 triple-axis crystal analyzer. Film densities were determined by fitting the XRR data using $X^{\prime}$ pert reflectivity software. Film hardness was determined with 20 indents for each sample, with a load of $50 \mathrm{mN}$ using a UMIS 2000 nanoindentation system.

\section{Quantum chemical calculations}

The investigated molecular structures were optimized at the density functional theory (DFT) level using the GGA functional $\mathrm{PBE}^{20}$ including an atomic pairwise dispersion correction scheme (DFT-D3(BJ)). ${ }^{21,22}$ Subsequently, the structures were optimized with MP2 and single-point calculations at the $\operatorname{CCSD}(\mathrm{T})$ level were carried out based on optimized MP2 structures. 
These calculations were performed with the def2-TZVPP ${ }^{23}$ basis set and the RI (DFT and MP2) ${ }^{24}$ as well as the MARIJ (for DFT) approximation. $^{25}$

Calculations were performed using Turbomole $6.6^{26}$ and Gaussian $09^{27}$ quantum chemistry codes by a combination of optimization algorithms from Gaussian with energies and gradients from Turbomole. MP2 and $\operatorname{CCSD}(\mathrm{T})$ calculations were carried out using the Turbomole module ricc2. In the case of DFT calculations, a fine integration grid (m4) was used and SCF convergence criteria were set to $10^{-9}$ a.u.

Initial guesses for transition states (TSs) were generated by the semi-empirical method $\mathrm{PM}^{28}$ and the TS optimization algorithm as well as the quadratic-synchronous transit method of Gaussian09. ${ }^{29}$ In some cases, existing TS structures from similar reactions of triethylaluminium or triethylgallium (TEGa) were used. ${ }^{30}$ The TS structures were refined with the TS optimization algorithm using PBE-D3(BJ)/def2-TZVPP and MP2/def2-TZVPP methods as outlined above. Intrinsic reaction coordinate calculations (IRC) were performed using Gaussian09. ${ }^{31}$ The identification of minima (no imaginary frequencies) and TS (one imaginary frequency) and the derivation of thermodynamic properties were achieved by calculations of the Hessian and derivation of vibrational spectra using Turbomole (aoforce module). Thermodynamic corrections of free atoms were computed using the Sackur-Tetrode equation. ${ }^{32}$ All closed-shell molecules exhibit singlet ground states, while all radicals were calculated in the doublet state. The thermodynamic corrections were computed at $T=400-1200{ }^{\circ} \mathrm{C}$ and $p=0.05$ atm (approx. 50 mbar). These settings represent typical CVD reactor conditions. Entropy corrections are sensitive to even small errors in the low-frequency vibrations of the molecule. Thus, absolute Gibbs energies at high temperatures have to be interpreted carefully. However, trends are less sensitive to this issue.

Based on Gibbs reaction energies $(\Delta G)$ and barriers $\left(\Delta G^{\dagger}\right)$ for the computed decomposition reactions, a kinetic Monte Carlo (KMC) simulation was performed to derive product distributions under different deposition conditions. Arrhenius-type reaction rates were considered within a temperature range of 600 to $1600 \mathrm{~K}\left(327-1327^{\circ} \mathrm{C}\right)$ applying a constant pre-exponential factor $\left(k_{\mathrm{B}} T / h\right.$, with $k_{\mathrm{B}}$ being the Boltzmann and $h$ the Planck constant) for all possible processes. Thermodynamic corrections for electronic energies were computed explicitly for selected temperatures (see above) and interpolated linearly. The system was modelled as a lattice-independent gas phase population with a relative concentration of the initial precursor TEB (0.5 mbar) of $1 \%$ with respect to the carrier gas $\left(\mathrm{H}_{2}\right.$ or $\mathrm{Ar}$, 50 mbar). The rate of each decomposition reaction was evaluated for each iteration and used to determine the individual probability of success, which is weighted against the total rate (sum of all possible process rates) for the system at the given state. Based on a random number check, one reaction was selected to take place against its probability and the system updated with the generated products of the process (and reactants annihilated). Each simulation was performed over 100000 iterations ensuring the system to reach equilibrium. Further details of the method will be reported elsewhere.

\section{Results and discussion}

\section{Deposited films}

Initial results for films deposited at $400-600{ }^{\circ} \mathrm{C}$ were reported in ref. 14. For a more complete picture of TEB as a CVD precursor for $\mathrm{B}_{x} \mathrm{C}$ films, we present results for films deposited at 700-1200 ${ }^{\circ} \mathrm{C}$ and include the low temperature results to show a wide temperature range from $400{ }^{\circ} \mathrm{C}$ to $1200{ }^{\circ} \mathrm{C}$.

Films appear black and shiny when they are deposited at 700-1000 ${ }^{\circ} \mathrm{C}$ in a $\mathrm{H}_{2}$ atmosphere and above $1000{ }^{\circ} \mathrm{C}$ get less shiny and vary in color more blacker. Films deposited in an $\mathrm{Ar}$ atmosphere also look black and shiny at 700-900 ${ }^{\circ} \mathrm{C}$, then tend to be more grayish and less shiny with increasing temperature. All deposited films adhere well to the Si(001) substrates regardless of the deposition atmosphere and are dense in typical crosssectional SEM images, as shown in Fig. 1(a). For films deposited above $900{ }^{\circ} \mathrm{C}$, voids are observed in the interface region in both atmospheres, which is likely the result of substrate and film solid state reaction, see Fig. 1(b), as it has been reported for $\mathrm{Si}(001)$ substrates used in CVD of SiC using silane and propane in $\mathrm{H}_{2}{ }^{33}$

The $\mathrm{B}$ and $\mathrm{C}$ content of the deposited films, as determined by ToF-ERDA, are given in Fig. 2. For the films deposited at up to $1000{ }^{\circ} \mathrm{C}$ in $\mathrm{a}_{2}$ atmosphere, $\mathrm{B}$ is the dominating element and increases slightly when the deposition temperature increases from $400{ }^{\circ} \mathrm{C}$ to $700{ }^{\circ} \mathrm{C}$ (71-82 at\%), while temperatures are in the range of $700-1000{ }^{\circ} \mathrm{C}$, the $\mathrm{B}$ content is more or less constant $\left(77 \pm 5\right.$ at\%). At further high temperatures, i.e., $1100{ }^{\circ} \mathrm{C}$ and $1200{ }^{\circ} \mathrm{C}$, B content drops drastically to 8 at $\%$. The $\mathrm{C}$ content in the films increases throughout the whole temperature range. At lower temperatures $\left(400-500{ }^{\circ} \mathrm{C}\right), \mathrm{C}$ content is less than 10 at $\%$ and varies between 17 and 28 at\% for temperatures between 600 and $1000{ }^{\circ} \mathrm{C}$. At highest temperatures, where the B content drops to 8 at\%, C content is as high as 92 at\%. The $\mathrm{C}$ enrichment in the films grown at the highest temperatures explains why they look blacker than the B-rich ones.

For depositions in an Ar atmosphere, B is again seen to be the dominant element in the films and follows the same trend as the films deposited in $\mathrm{H}_{2}$ : increases with increasing deposition temperature at $400-600{ }^{\circ} \mathrm{C}(56-76$ at $\%)$, fairly stable at $600-1000{ }^{\circ} \mathrm{C}$ (71 \pm 1 at $\%$ ), and significantly decreases at temperatures above

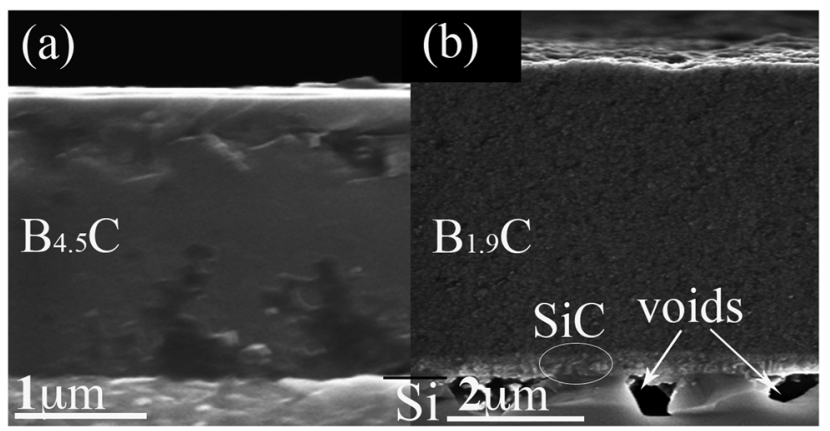

Fig. 1 Cross-sectional SEM images, showing $\mathrm{B}_{x} \mathrm{C}$ films deposited onto $\mathrm{Si}(001)$ at (a) $700{ }^{\circ} \mathrm{C}$ in a $\mathrm{H}_{2}$ atmosphere and (b) $1100{ }^{\circ} \mathrm{C}$ in an $\mathrm{Ar}$ atmosphere showing film-to-substrate interface reaction with void and $\mathrm{SiC}$ formation. 


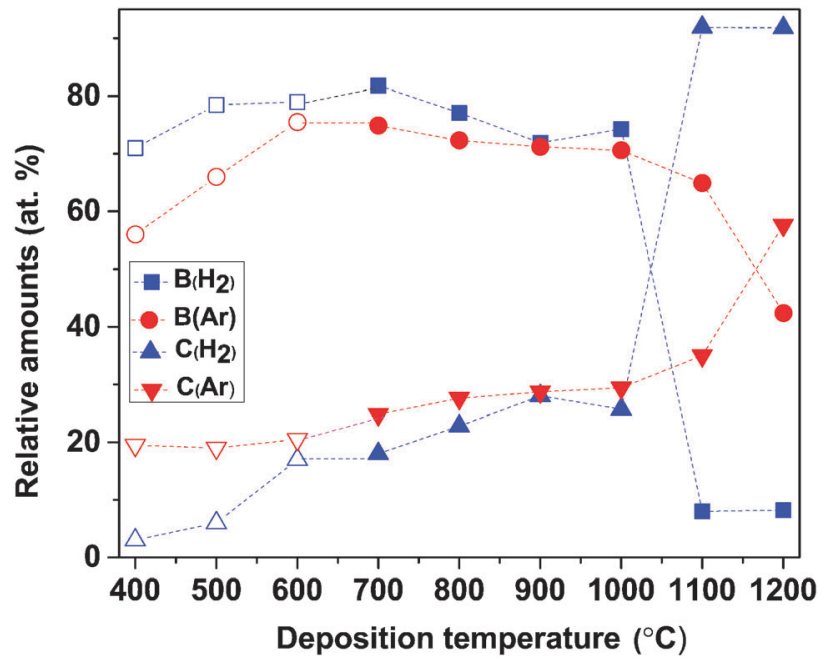

Fig. 2 ToF-ERDA data showing the relative amounts of $B$ and $C$ of films deposited in $\mathrm{H}_{2}$ and $\mathrm{Ar}$ atmospheres, respectively, as a function of deposition temperature. Open symbols correspond to data points taken from our previous publication. ${ }^{14}$

$1000{ }^{\circ} \mathrm{C}$, see Fig. 2. The $\mathrm{C}$ content in the films deposited in an Ar atmosphere reveals three functions of the temperature range: in the range of $400-600{ }^{\circ} \mathrm{C}$, it is constant at $\sim 20$ at $\%$ and increases gradually from 25 to 35 at\%; when the temperature increases from 600 to $1100{ }^{\circ} \mathrm{C}$, at $1200{ }^{\circ} \mathrm{C}$ reaches its maximum of $58 \mathrm{at} \%$. The lower $\mathrm{C}$ content in the films, compared to that obtained in $\mathrm{H}_{2}$, can explain why films deposited in Ar look greyish while those deposited in $\mathrm{H}_{2}$ became more blacker at temperatures above $1000{ }^{\circ} \mathrm{C}$.

In Fig. 3, the B-to-C $(\mathrm{B} / \mathrm{C})$ ratios are plotted as a function of deposition temperature. It shows that at lower temperatures (400 and $500{ }^{\circ} \mathrm{C}$ ), $\mathrm{B} / \mathrm{C}$ ratios in $\mathrm{H}_{2}$ deviate from the $\mathrm{B} / \mathrm{C}$ ratios in Ar. At higher temperature $\left(600-1000{ }^{\circ} \mathrm{C}\right)$ the difference between

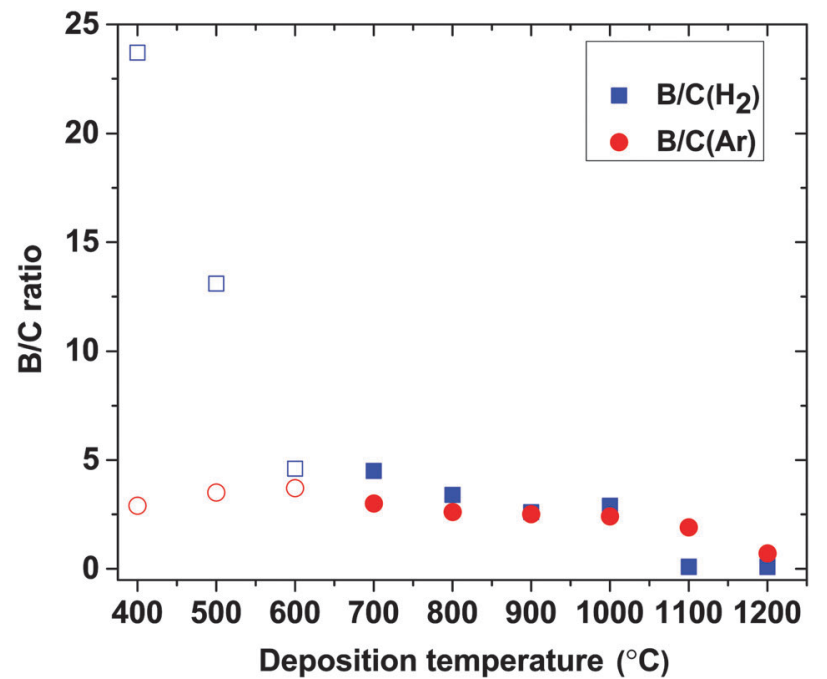

Fig. $3 \mathrm{~B} / \mathrm{C}$ ratios in $\mathrm{H}_{2}$ and $\mathrm{Ar}$ atmospheres as a function of deposition temperature. Open symbols correspond to data points taken from our previous publication. ${ }^{14}$

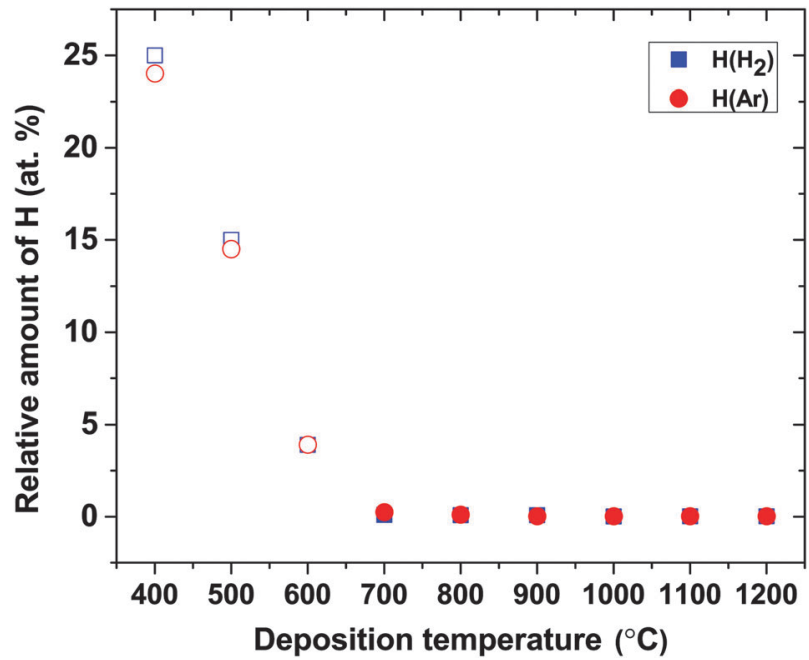

Fig. 4 ToF-ERDA data showing the relative amount of $\mathrm{H}$ in $\mathrm{H}_{2}$ and $\mathrm{Ar}$ atmospheres, respectively, as a function of deposition temperature. Open symbols correspond to data points taken from our previous publication. ${ }^{14}$

the two atmospheres decreases with increasing temperature. As it is noted above, the abrupt drop in B content (and increase in $\mathrm{C}$ ) above $1000{ }^{\circ} \mathrm{C}$ results in the lowest $\mathrm{B} / \mathrm{C}$ ratio in $\mathrm{H}_{2}$ while in $\mathrm{Ar}$, it slightly decreases with increasing temperature.

In Fig. 4 , the $\mathrm{H}$ content in the films is plotted as a function of temperature. It can be seen that $\mathrm{H}$ is not affected by the deposition atmosphere, but solely by deposition temperature, which suggests that any $\mathrm{H}$ in the films originates from the TEB precursor rather than from the carrier gas. By increasing temperature from $400{ }^{\circ} \mathrm{C}$ to $600{ }^{\circ} \mathrm{C}, \mathrm{H}$ content in the films drops from 24 to 4 at $\%$. For temperatures above $600{ }^{\circ} \mathrm{C}, \mathrm{H}$ levels are constantly below 1 at $\%$ showing that these temperatures enable depositions of nearly $\mathrm{H}$-free films. This temperature dependent decrease in $\mathrm{H}$ content suggests that either an out diffusion of $\mathrm{H}$ from the films and/or a more favorable surface chemistry is activated only for deposition temperatures higher than $600{ }^{\circ} \mathrm{C}$. Detailed elemental compositions in all films are given in ESI, $\dagger$ Table S1. For films deposited below $700{ }^{\circ} \mathrm{C}$, oxygen (O) contamination in the films is as low as $0.5-1$ at $\%{ }^{14}$ while for films deposited at temperatures above $700{ }^{\circ} \mathrm{C}$, the amount of $\mathrm{O}$ is below the detection limit. Other impurities, like $\mathrm{N}$ and $\mathrm{Ar}$, are below the detection limit for ToF-ERDA of 0.05 at\%.

The deposition rate varies with both the deposition atmosphere and temperature, as shown in Fig. 5. Generally, a higher deposition rate is obtained in Ar, which indicates that films are etched more in $\mathrm{a}_{2}$ atmosphere than in Ar. In both atmospheres (within the temperature range giving B-rich films), the deposition rates increase with increasing temperature and maxima of $2 \mu \mathrm{m} \mathrm{h}^{-1}$ in $\mathrm{H}_{2}$ and $4.5 \mu \mathrm{m} \mathrm{h}^{-1}$ in Ar are obtained at $900{ }^{\circ} \mathrm{C}$. The deposition rate increases again starting from $1000{ }^{\circ} \mathrm{C}$ in $\mathrm{H}_{2}$ and $1100{ }^{\circ} \mathrm{C}$ in $\mathrm{Ar}$, respectively. These observed variations in the deposition rate and the $\mathrm{B} / \mathrm{C}$ ratio with deposition temperature (Fig. 3) in combination with the elemental composition of the films described above imply that the deposition chemistry changes substantially with temperature, 


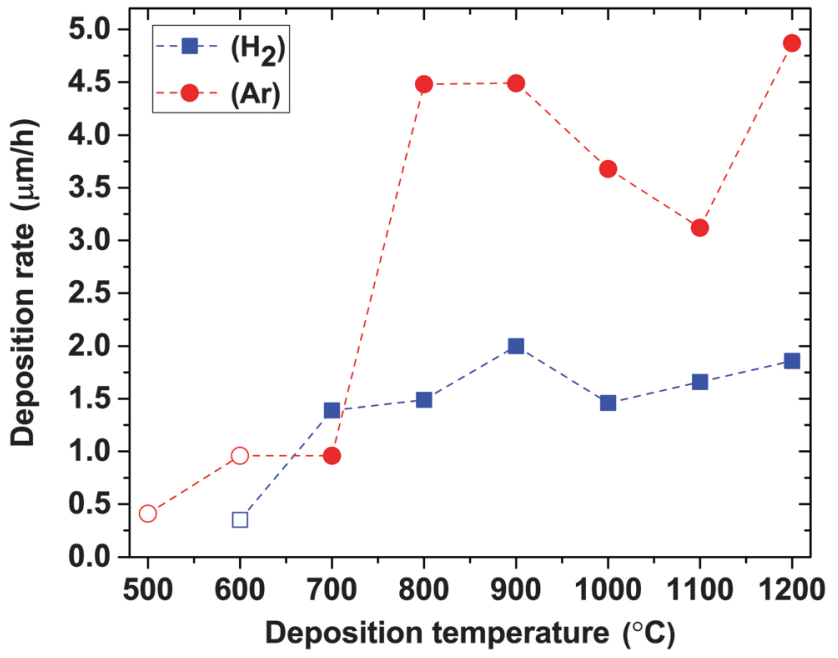

Fig. 5 Deposition rates in $\mathrm{H}_{2}$ and $\mathrm{Ar}$ atmospheres as a function of deposition temperature. Open symbols correspond to data points taken from our previous publication. ${ }^{14}$

as discussed below. Estimations of activation energy for CVD of $\mathrm{B}_{x} \mathrm{C}$ films from TEB by the Arrhenius plot are thus not meaningful.

Regardless of the deposition atmosphere, all films deposited at $1000{ }^{\circ} \mathrm{C}$ or below are X-ray amorphous, as shown for films deposited at 700-1200 ${ }^{\circ} \mathrm{C}$ in Fig. 6 and as previously reported for films deposited at $400-600{ }^{\circ} \mathrm{C}$. ${ }^{14}$ The peak that is seen at $26.3^{\circ}$ for films deposited at $1100{ }^{\circ} \mathrm{C}$ and $1200{ }^{\circ} \mathrm{C}$ is more distinct for films deposited in $\mathrm{H}_{2}$ (Fig. 1(a)) than Ar (Fig. 1(b)) atmospheres where the peaks are much broader, and is assigned to the 002 peak of graphite. ${ }^{34}$ This matches well with the high $\mathrm{C}$ content in the films deposited at these temperatures as described above. The small peak with very low intensity initiating at around $60^{\circ}$ is also found to be very close to the 103 peak of graphite. Besides the graphite peaks, one more peak is seen at $41.3^{\circ}$, which fits well with the 002 peak of $3 \mathrm{C}-\mathrm{SiC},{ }^{35}$ in agreement with the observed interface reaction at high temperatures $\left(>900{ }^{\circ} \mathrm{C}\right)$, see Fig. 1(b). The lack of the Si signal in the ERDA analysis is due to the limited depth sampling in our experiments not reaching the film/substrate interface region. According to their peak positions, the two broad bumps arising at $35^{\circ}$ and $38^{\circ}$ in an Ar atmosphere are assumed to be originated from peaks 002 and 112 of $\mathrm{B}_{50} \mathrm{C}_{1.8}$.

The densities of selected films are listed in ESI, $\uparrow$ Table S2. Films with $\mathrm{B} / \mathrm{C}$ ratios of about 4.5 , deposited at $600{ }^{\circ} \mathrm{C}$ and $700{ }^{\circ} \mathrm{C}$ in $\mathrm{a} \mathrm{H}_{2}$ atmosphere, have gravimetric densities of $2.42 \pm 0.05 \mathrm{~g} \mathrm{~cm}^{-3}$, which are close to the bulk density ${ }^{36}$ of $\mathrm{B}_{4} \mathrm{C}: 2.52 \mathrm{~g} \mathrm{~cm}^{-3}$ as well as the density of sputtered films: ${ }^{6}$ $2.45 \mathrm{~g} \mathrm{~cm}^{-3}$. Relatively high film hardness, in the range of 37-39 GPa, is measured for the amorphous $\mathrm{B}_{x} \mathrm{C}$ films deposited at $800-900{ }^{\circ} \mathrm{C}$. The hardness and the bending shape of samples (most clear for films deposited in $\mathrm{Ar}$ ) indicate that films experienced internal compressive stresses. More details of the measured film hardness are given in ESI, $\dagger$ Fig. S1.

\section{Computational investigation of TEB decomposition reactions}

Quantum chemical computations at the DFT and wave function based MP2 and $\operatorname{CCSD}(\mathrm{T})$ levels are carried out to understand

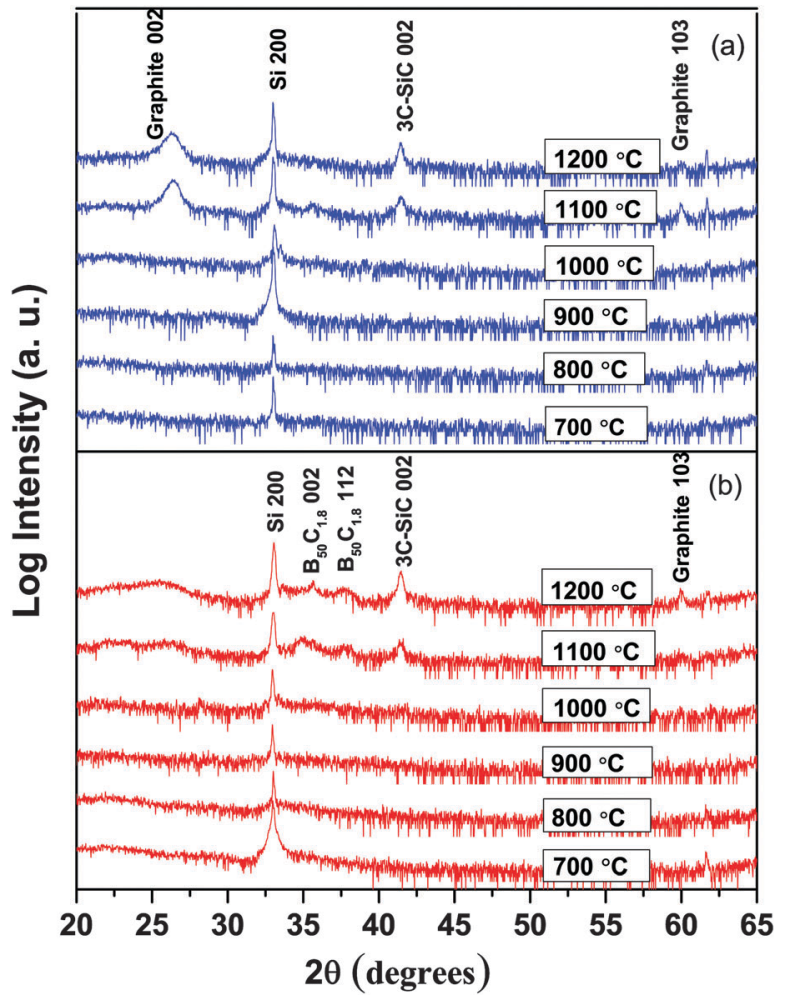

Fig. $6 \mathrm{X}$-ray diffractograms of $\mathrm{B}_{x} \mathrm{C}$ films deposited at temperatures between 700 and $1200{ }^{\circ} \mathrm{C}$ in (a) $\mathrm{H}_{2}$ and (b) Ar atmospheres.

the elementary reactions of TEB occurring in the gas phase. To this end, a large catalogue of uni-molecular decomposition reactions for TEB has been set up and augmented by $\mathrm{H}_{2}$-assisted decomposition reactions to elucidate the role of the carrier gas $\left(\mathrm{H}_{2}\right.$ or $\left.\mathrm{Ar}\right)$ as found in the experimental part described above. As a starting point for the reaction catalogue, our previous work on the gas phase reactivity of TEGa is used. ${ }^{30}$ Five possible reaction types are studied in this work: (a) radical cleavages, (b) $\beta$-hydride eliminations, (c) alkane eliminations, (d) $\mathrm{H}_{2}$-eliminations, and (e) $\alpha$-H-abstraction reactions. We summarize the major findings from this large set of reactions. The complete reaction catalogue and thermodynamic data for different temperatures as well as a test of the DFT methodology can be found in the ESI. $\dagger$

Most of the reactions investigated are endergonic under the given conditions. The electronic reaction energies of radical cleavages are in the range of $300-500 \mathrm{~kJ} \mathrm{~mol}^{-1}$ and the Gibbs energies for nearly all reactions are above $200 \mathrm{~kJ} \mathrm{~mol}^{-1}$ even at temperatures above $700{ }^{\circ} \mathrm{C}$. The reaction energies of most alkane and $\mathrm{H}_{2}$ eliminations are in the same range, whereby the Gibbs reaction energies at high temperatures are slightly lower due to high entropic contributions. One $\alpha-\mathrm{H}$ elimination reaction that results in ethane as a reaction product and one $\alpha-\mathrm{H}$ abstraction of TEB (see ESI, $\dagger$ Fig. S2) are found to be thermodynamically accessible $\left(\Delta G<0 \mathrm{~kJ} \mathrm{~mol}^{-1}\right.$ for $\left.T>500{ }^{\circ} \mathrm{C}\right)$. Most importantly, the $\beta$-hydride eliminations are thermodynamically accessible at temperatures $T>500{ }^{\circ} \mathrm{C}$ for the TEB precursor as well as the resulting intermediates (reactions (3)-(5) in Table 1). For these exergonic or slightly endergonic reactions, 
Table 1 Computed reaction $(\Delta E)$ and Gibbs energies $(\Delta G)$ together with reaction barriers $\left(\Delta E^{\dagger}, \Delta G^{\dagger}\right)$ for the major decomposition channels of $\mathrm{TEB}^{\mathrm{a}}$

\begin{tabular}{lllll}
\hline Reaction & $\Delta E$ & $\Delta G$ & $\Delta E^{\dagger}$ & $\Delta G^{\dagger}$ \\
\hline
\end{tabular}

$\beta$-Hydride elimination

(3) $\mathrm{B}\left(\mathrm{C}_{2} \mathrm{H}_{5}\right)_{3} \rightarrow \mathrm{B}\left(\mathrm{C}_{2} \mathrm{H}_{5}\right)_{2} \mathrm{H}+\mathrm{C}_{2} \mathrm{H}_{4}$

(4) $\mathrm{B}\left(\mathrm{C}_{2} \mathrm{H}_{5}\right)_{2} \mathrm{H} \rightarrow \mathrm{B}\left(\mathrm{C}_{2} \mathrm{H}_{5}\right) \mathrm{H}_{2}+\mathrm{C}_{2} \mathrm{H}_{4}$

(5) $\mathrm{B}\left(\mathrm{C}_{2} \mathrm{H}_{5}\right) \mathrm{H}_{2} \rightarrow \mathrm{BH}_{3}+\mathrm{C}_{2} \mathrm{H}_{4}$

$156.5 \quad-5.4 \quad 156.9 \quad 169.6^{b}$ $160.9+12.3 \quad 160.9^{b} \quad 187.9^{b}$ $165.5+16.5165 .5^{b} 173.6^{b}$

$\mathrm{H}_{2}$-Assisted ethane elimination

(6) $\mathrm{B}\left(\mathrm{C}_{2} \mathrm{H}_{5}\right)_{3}+\mathrm{H}_{2} \rightarrow \mathrm{B}\left(\mathrm{C}_{2} \mathrm{H}_{5}\right)_{2} \mathrm{H}+\mathrm{C}_{2} \mathrm{H}_{6} \quad-15.9 \quad-31.7 \quad 71.5 \quad 239.1$

(7) $\mathrm{B}\left(\mathrm{C}_{2} \mathrm{H}_{5}\right)_{2} \mathrm{H}+\mathrm{H}_{2} \rightarrow \mathrm{B}\left(\mathrm{C}_{2} \mathrm{H}_{5}\right) \mathrm{H}_{2}+\mathrm{C}_{2} \mathrm{H}_{6}-11.6-14.2 \quad 47.3 \quad 210.3$

(8) $\mathrm{B}\left(\mathrm{C}_{2} \mathrm{H}_{5}\right) \mathrm{H}_{2}+\mathrm{H}_{2} \rightarrow \mathrm{BH}_{3}+\mathrm{C}_{2} \mathrm{H}_{6} \quad-7.1-10.0 \quad 18.3 \quad 163.9$

${ }^{a}$ All values in $\mathrm{kJ} \mathrm{mol}^{-1}$ computed with PBE-D3/def2-TZVPP. Gibbs energies given for $p=0.05 \mathrm{~atm}$ and $T=500{ }^{\circ} \mathrm{C}$. See ESI for further details. ${ }^{b}$ No TS can be located for these reactions (see the text). Thermodynamic corrections are taken from TEGa (see the text for details). ${ }^{30}$

TS searches are also carried out. It is found that the reaction barriers for all uni-molecular reactions lie above $200 \mathrm{~kJ} \mathrm{~mol}^{-1}$ $\left(T=500{ }^{\circ} \mathrm{C}\right)$ except for the $\beta$-hydride eliminations shown in Table 1.

The TSs of the $\beta$-hydride elimination reactions warrant a brief discussion. The potential energy surface for the first elimination reaction (3) exhibits one TS, which lies only $0.4 \mathrm{~kJ} \mathrm{~mol}^{-1}$ above the products. The TS structure in Fig. 7(a) underlines this with very long $\mathrm{B}-\mathrm{C}(2.53 \AA)$ and $\mathrm{B}-\mathrm{H}(2.47 \AA)$ bond distances and a $\mathrm{C}-\mathrm{C}$ bond distance in $\mathrm{C}_{2} \mathrm{H}_{4}$ units, which is already matching the bond length in the product (1.34 ̊̊). For reactions (4) and (5), no TS is found. Thus, we consider the reverse process - association of $\mathrm{C}_{2} \mathrm{H}_{4}$ with $\mathrm{BHR}_{2}\left(\mathrm{R}=\mathrm{H}, \mathrm{C}_{2} \mathrm{H}_{5}\right)$ to be a non-activated process. The reaction barrier for reactions (4) and (5) is thus equal to the electronic energy difference $\Delta E$ between reactants and products. To estimate the free energy contribution to the reaction barrier for reactions (3)-(5), we take the thermodynamic corrections from the respective reactions of TEGa. ${ }^{30}$

Besides the uni-molecular reactions, three $\mathrm{H}_{2}$-assisted ethane eliminations have been studied (reactions (6)-(8) in Table 1). They exhibit negative reaction and exothermic Gibbs energies. Electronic barriers are small, while Gibbs energy barriers are significantly higher than the corresponding barriers for $\beta$-hydride eliminations. The TS structures are midway between reactants and products (Fig. 7(b) for reaction (6)). The $\mathrm{H}-\mathrm{H}$ bond is strongly activated $\left(d(\mathrm{H}-\mathrm{H})=1.08 \AA\right.$ versus $0.75 \AA$ in $\left.\mathrm{H}_{2}\right)$, while the $\mathrm{B}-\mathrm{H}$-bond length is already rather short (1.31 A versus $1.21 \AA$ in the product)

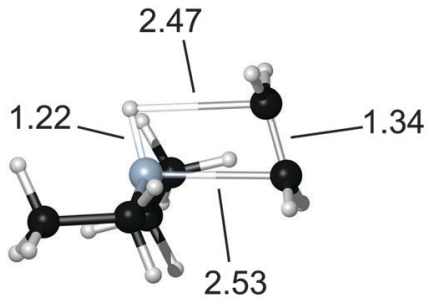

a) TS of reaction (3)

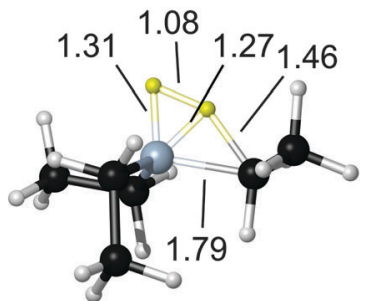

b) TS of reaction (6)
Fig. 7 TS structures for reactions (3) and (6) at PBE-D3/def2-TZVPP with selected structural parameters in $\AA$. See Table 1 for reaction numbering. and the distance of the newly developing $\mathrm{C}-\mathrm{H}$-bond is still quite large ( $1.46 \AA$ versus $1.09 \AA$ in the product). The carbon-boron bond is stretched from $1.55 \AA$ to $1.79 \AA$. The strong increase of the barrier at higher temperatures can be attributed to a loss of entropy from transferring two flexible reactant molecules to one species with fewer degrees of freedom at the TS.

The reaction energies and barriers evaluated at the MP2 level of approximation are generally in good agreement with the DFT values. Coupled cluster benchmark values at $\operatorname{CCSD}(\mathrm{T})$ support the validity of the methodology chosen as outlined previously for TEGa. ${ }^{30}$ Details can be found in the ESI. $\dagger$

\section{Gas phase CVD chemistry of TEB}

Based on the experimental and computational results outlined above, we now discuss possible gas phase CVD chemistry for TEB. In our previous low temperature CVD study,${ }^{14}$ we sketched a chemical reaction mechanism for CVD of $\mathrm{B}_{x} \mathrm{C}$ films from TEB based on $\beta$-hydride elimination of ethylene $\left(\mathrm{C}_{2} \mathrm{H}_{4}\right)$.

This reaction was previously reported to occur at $300{ }^{\circ} \mathrm{C},{ }^{16}$ and thus it was suggested that at temperatures higher than $300{ }^{\circ} \mathrm{C}$, the other two ethyl groups could also be eliminated to form $\mathrm{BH}_{3}{ }^{14}$ This is in line with the quantum chemical computations in the present study (reactions (3)-(5) in Table 1), which shows the lowest barriers and the most favorable thermodynamic values for this reaction type.

The product distribution under different reaction conditions can now be determined via a list-based KMC simulation based on the full set of reactions. In line with the arguments presented above, only the reactions in Table 1 provide sizeable contributions to the product distributions. Fig. 8 shows the KMC simulations for the reaction catalogue with (Fig. 8(a)) and without (Fig. 8(b)) considering reactions with $\mathrm{H}_{2}$. This simulates the growth in $\mathrm{H}_{2}$ and $\mathrm{Ar}$ atmospheres since in the latter case, reactions with $\mathrm{H}_{2}$ is not possible. Both simulations show a rapid decrease of the reactant TEB with increasing temperature, while the intermediates $\left(\mathrm{B}\left(\mathrm{C}_{2} \mathrm{H}_{5}\right)_{2} \mathrm{H}\right.$ and $\left.\mathrm{B}\left(\mathrm{C}_{2} \mathrm{H}_{5}\right) \mathrm{H}_{2}\right)$ and product $\left(\mathrm{BH}_{3}\right)$ of the $\beta$-hydride elimination reaction are dominant in the gas phase. The importance of $\beta$-hydride elimination reactions for the decomposition of group 13 precursors was also found previously for $\mathrm{TEGa}^{30}$ and even for group 15 compounds. ${ }^{37,38}$ From Table 1 , it is found that $\beta$-hydride eliminations exhibit moderately high electronic barriers, which increase only slightly with increasing temperature. The $\mathrm{H}_{2}$-assisted ethane eliminations on the other hand show small barriers with a strong increase at higher temperatures due to entropic effects. These reactions should thus only be important at lower temperatures. In Fig. 8(a), the concentration of $\mathrm{C}_{2} \mathrm{H}_{6}$ is an indicator for the $\mathrm{H}_{2}$-assisted reactions thus it is present when considering reactions (6)-(8) and absent in Fig. 8(b), which mimics the Ar atmosphere. Thus, the bimolecular reactions contribute to the reaction rate at low temperatures only in the presence of $\mathrm{H}_{2}$.

The origin of $\mathrm{C}$ in the deposited films is most likely the $\mathrm{C}_{2} \mathrm{H}_{4}$ formed by the $\beta$-hydride elimination at all temperatures in the 


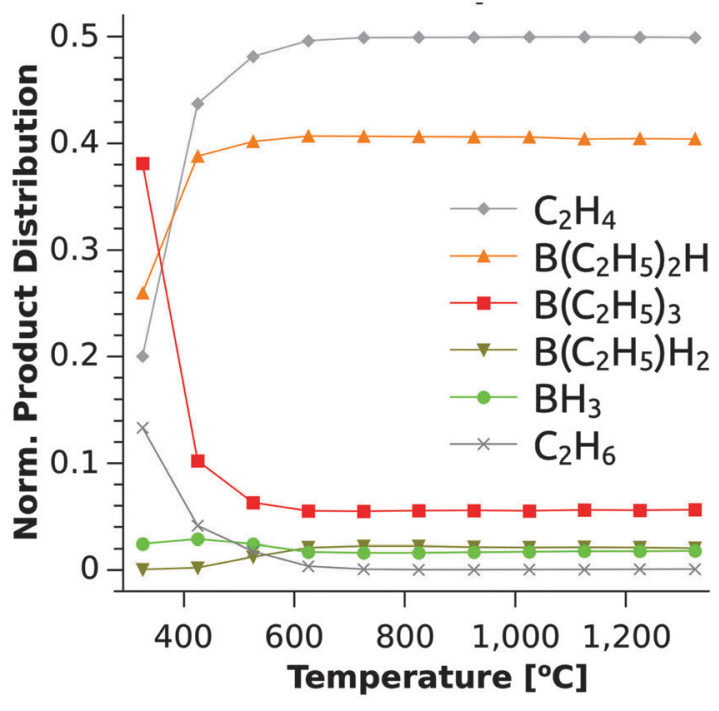

(a)

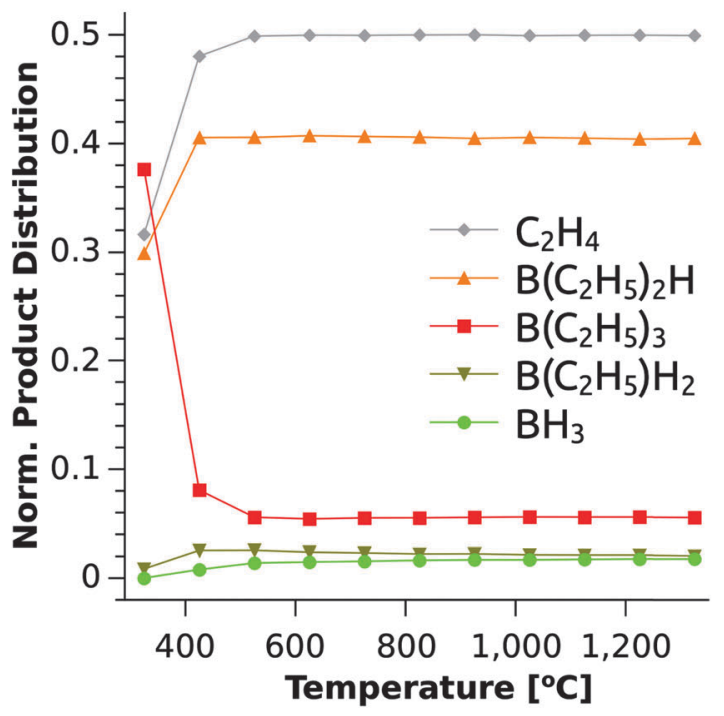

(b)

Fig. 8 Product distribution derived from KMC simulation under CVD conditions for varying temperatures. Simulation of the full reaction catalogue (a) with ( $\mathrm{H}_{2}$ atmosphere) and (b) without (Ar atmosphere) reactions (6)-(8). See Table 1 for reaction numbering

simulation (Fig. 8), or $\mathrm{C}_{2} \mathrm{H}_{2}$, which is produced by $\mathrm{H}_{2}$ elimination from $\mathrm{C}_{2} \mathrm{H}_{4} \cdot{ }^{39}$ The reactivity of these hydrocarbons is likely low at the lowest temperatures studied giving rise to rather low $\mathrm{C}$ contents in the films despite the $\mathrm{B} / \mathrm{C}$ ratio of $1 / 6$ in the TEB molecule. The gradual increase in $\mathrm{C}$ content when the deposition temperature is increased to $1000{ }^{\circ} \mathrm{C}$ can be explained by a higher reactivity for the hydrocarbons at higher temperatures.

The $\mathrm{C}_{2} \mathrm{H}_{6}$ molecules produced in $\mathrm{H}_{2}$-assisted $\mathrm{C}_{2} \mathrm{H}_{6}$ elimination will likely decompose to methyl radicals $\left({ }^{\bullet} \mathrm{CH}_{3}\right)$, by cleaving the $\mathrm{C}-\mathrm{C}$ single bond, ${ }^{40,41}$ which would then form $\mathrm{CH}_{4}$ together with the $\mathrm{H}_{2}$ carrier gas. Being the hydrocarbon with the highest symmetry, $\mathrm{CH}_{4}$ is expected to be nonreactive at the lowest deposition temperatures. The formation of less reactive hydrocarbon species together with an increased $\mathrm{BH}_{3}$ formation further explains the significantly higher $\mathrm{B} / \mathrm{C}$ ratio in films deposited at low temperature in a $\mathrm{H}_{2}$ atmosphere. For deposition at higher temperatures $\left(600{ }^{\circ} \mathrm{C}<T<1000{ }^{\circ} \mathrm{C}\right)$ in a $\mathrm{H}_{2}$ atmosphere, $\mathrm{C}_{2} \mathrm{H}_{4}$ is mainly formed through $\beta$-hydride elimination (Table 1 ), which is more reactive than $\mathrm{CH}_{4}$, and thus the films are deposited with higher $\mathrm{C}$ content, see Fig. 2.

The formation of $\mathrm{C}_{2} \mathrm{H}_{6}$ by reactions (6)-(8) is not available in an Ar atmosphere and the TEB molecule is forced to decompose only via $\beta$-hydride elimination. Thus, reactive $\mathrm{C}_{2} \mathrm{H}_{4}$ is the dominating C-carrying molecule in Ar regardless of deposition temperature (Fig. 8(b)) leading to a more stable $\mathrm{B} / \mathrm{C}$ ratio with temperature up to $600{ }^{\circ} \mathrm{C}$ and increases slightly with the increasing degree of $\beta$-hydride elimination at further high temperatures.

Although, the $\beta$-hydride elimination is more accessible at higher temperatures, the $\mathrm{B}$ content in the films decreases from $700{ }^{\circ} \mathrm{C}$ and shows a significant decrease at $T>1000{ }^{\circ} \mathrm{C}$. This is likely caused by the hydrocarbons being more reactive with higher temperatures, leading to more $\mathrm{C}$ being deposited. This effect is most clear in a $\mathrm{H}_{2}$ atmosphere, which could be due to the higher $\mathrm{B}$ etching on the surface in the presence of $\mathrm{H}_{2}$ carrier gas, which is not the case in an Ar atmosphere (see Fig. 2).

CVD of BN using TEB as a boron precursor is typically done in a $\mathrm{H}_{2}$ atmosphere at temperatures above $1000{ }^{\circ} \mathrm{C}$ and from our results it can be concluded that at this temperature at least one, likely more than one, of the ethyl groups on TEB is eliminated by $\beta$-hydride elimination. The boron species active for $\mathrm{BN}$ formation are thus $\mathrm{BH}_{3}, \mathrm{~B}\left(\mathrm{C}_{2} \mathrm{H}_{5}\right) \mathrm{H}_{2}$ and $\mathrm{B}\left(\mathrm{C}_{2} \mathrm{H}_{5}\right)_{2} \mathrm{H}$. The problem one faces when using TEB for CVD of $\mathrm{BN}$ is the formation of the hydrocarbons as by-products. The incorporation of carbon into BN is unwanted and a significant risk at temperatures above $1000{ }^{\circ} \mathrm{C}$ is shown by our results. The CVD chemistry (both gas phase- and surface chemistry) of the nitrogen precursor, typically $\mathrm{NH}_{3}$, is crucial for the formation of a $\mathrm{BN}$ instead of a boron carbide or a boron carbonitride.

\section{Conclusions}

From our results we conclude that the gas phase CVD chemistry of TEB is dominated by $\beta$-hydride eliminations of $\mathrm{C}_{2} \mathrm{H}_{4}$ to finally yield $\mathrm{BH}_{3}$ (reactions (3)-(5)). $\mathrm{C}_{2} \mathrm{H}_{4}$ is at least partly expected to undergo $\mathrm{H}_{2}$ elimination to $\mathrm{C}_{2} \mathrm{H}_{2}$ and it is thus likely that $\mathrm{BH}_{3}$, $\mathrm{C}_{2} \mathrm{H}_{4}$ and $\mathrm{C}_{2} \mathrm{H}_{2}$ are the active species for the deposition of $\mathrm{B}_{x} \mathrm{C}$. In a $\mathrm{H}_{2}$ atmosphere, a $\mathrm{H}_{2}$-assisted $\mathrm{C}_{2} \mathrm{H}_{6}$ elimination path to $\mathrm{BH}_{3}$ (reactions (6)-(8)) can be of importance at lower temperatures. The formed $\mathrm{C}_{2} \mathrm{H}_{6}$ is expected to decompose to methyl radicals, which subsequently forms methane with hydrogen. The low reactivity of $\mathrm{CH}_{4}$ at low temperatures leads to very B-rich films. We also find that CVD of $\mathrm{B}_{x} \mathrm{C}$ thin films using TEB as a 
single-source precursor produces X-ray amorphous films with $2.5 \leq x \leq 4.5$ and low $\mathrm{H}$ content in a temperature range of 600-1000 ${ }^{\circ} \mathrm{C}$ in both $\mathrm{H}_{2}$ and $\mathrm{Ar}$ atmospheres. Depositions at lower temperatures result in high $\mathrm{H}$ incorporation while higher temperatures in C-rich films. The quantum chemical calculations produced a comprehensive reaction catalogue for the gas phase chemistry of TEB including thermochemical data under CVD conditions.

\section{Acknowledgements}

Financial support from European Spallation Source ESS AB, the Knut and Alice Wallenberg Foundation, the German Science Foundation (Research Training Group 1782) and the Beilstein Foundation (Frankfurt/Germany) is gratefully acknowledged. The authors would like to acknowledge the Tandem Laboratory at Uppsala University for giving access to their ion beam facilities and Dr Lina Rogström is acknowledged for her help with nanoindentation measurements and useful discussions. We also thank the HRZ Marburg for computational resources.

\section{References}

1 J. C. Oliveira, M. N. Oliveira and O. Conde, Surf. Coat. Technol., 1996, 80, 100-104.

2 K.-W. Lee and S. J. Harris, Diamond Relat. Mater., 1998, 7, 1539-1543.

3 M. Bouchacourt and F. Thevenot, J. Less-Common Met., 1981, 82, 219-226.

4 M. Chubarov, H. Pedersen, H. Högberg, S. Filippov, J. A. A. Engelbrecht, J. O'Connel and A. Henry, Phys. B, 2014, 439, 29-34.

5 A. Geim and I. V. Grigorieva, Nature, 2013, 499, 419-425.

6 C. Höglund, J. Birch, K. Andersen, T. Bigault, J. C. Buffet, J. Correa, P. Van Esch, B. Guerard, R. Hall-Wilton, J. Jensen, A. Khaplanov, F. Piscitelli, C. Vettier, W. Vollenberg and L. Hultman, J. Appl. Phys., 2012, 111, 104908.

7 J. Li, R. Dahal, S. Majety, J. Y. Lin and H. X. Jiang, Nucl. Instrum. Methods Phys. Res., Sect. A, 2011, 654, 417-420.

8 K. Andersen, T. Bigault, J. Birch, J. C. Buffet, J. Correa, R. Hall-Wilton, L. Hultman, C. Höglund, B. Guérard, J. Jensen, A. Khaplanov, O. Kirstein, F. Piscitelli, P. Van Esch and C. Vettier, Nucl. Instrum. Methods Phys. Res., Sect. A, 2013, 720, 116-121.

9 D. Kramer, Phys. Today, 2011, 64, 20-23.

10 U. Jansson, J.-O. Carlsson, B. Stridh, S. Söderberg and M. Olsson, Thin Solid Films, 1989, 172, 81-93.

11 A. Pakdel, Y. Bando and D. Golberg, Chem. Soc. Rev., 2014, 43, 934-959.

12 CRC Handbook of Chemistry and Physics, ed. W. M. Haynes, CRC Press, Boca Raton, FL, 95th edn, 2014, pp. 3-526.

13 National Institute of Standards and Technology (NIST) Webbook: http://webbook.nist.gov/cgi/cbook.cgi?ID=C97949\& Mask=1A8F, accessed 2015-05-25.
14 H. Pedersen, C. Höglund, J. Birch, J. Jensen and A. Henry, Chem. Vap. Deposition, 2012, 18, 221-224.

15 M. Chubarov, H. Pedersen, H. Högberg, J. Jensen and A. Henry, Cryst. Growth Des., 2012, 12, 3215-3220.

16 J. S. Lewis, S. Vaidyaraman, W. J. Lackey, P. K. Agrawal, G. B. Freeman and E. K. Barefield, Mater. Lett., 1996, 27, 327-332.

17 A. Henry, J. Hassan, J. P. Bergman, C. Hallin and E. Janzén, Chem. Vap. Deposition, 2006, 12, 475-482.

18 J. Jensen, D. Martin, A. Surpi and T. Kubart, Nucl. Instrum. Methods Phys. Res., Sect. B, 2010, 268, 1893-1898.

19 H. J. Whitlow, G. Possnert and C. S. Petersson, Nucl. Instrum. Methods Phys. Res., Sect. B, 1987, 27, 448-457.

20 J. Perdew, K. Burke and M. Ernzerhof, Phys. Rev. Lett., 1996, 77, 3865-3868.

21 S. Grimme, J. Antony, S. Ehrlich and H. Krieg, J. Chem. Phys., 2010, 132, 154104.

22 S. Grimme, S. Ehrlich and L. Goerigk, J. Comput. Chem., 2011, 32, 1456-1465.

23 F. Weigend and R. Ahlrichs, Phys. Chem. Chem. Phys., 2005, 7, 3297-3305.

24 R. Ahlrichs, Phys. Chem. Chem. Phys., 2004, 6, 5119-5121.

25 M. Sierka, A. Hogekamp and R. Ahlrichs, J. Chem. Phys., 2003, 118, 9136-9148.

26 Turbomole, 6.6, 2014, a development of University of Karlsruhe and Forschungszentrum Karlsruhe $\mathrm{GmbH}$, 1989-2007, Turbomole GmbH, since 2007; available from http://www.turbomole.com.

27 M. J. Frisch, G. W. Trucks, H. B. Schlegel, G. E. Scuseria, M. A. Robb, J. R. Cheeseman, G. Scalmani, V. Barone, B. Mennucci, G. A. Petersson, H. Nakatsuji, M. Caricato, X. Li, H. P. Hratchian, A. F. Iz-maylov, J. Bloino, G. Zheng, J. L. Sonnenberg, M. Hada, M. Ehara, K. Toyota, R. Fukuda, J. Hasegawa, M. Ishida, T. Nakajima, Y. Honda, O. Kitao, H. Nakai, T. Vreven, J. A. Montgomery, Jr., J. E. Peralta, F. Ogliaro, M. Bearpark, J. J. Heyd, E. Brothers, K. N. Kudin, V. N. Staroverov, R. Kobayashi, J. Normand, K. Raghavachari, A. Rendell, J. C. Burant, S. S. Iyengar, J. Tomasi, M. Cossi, N. Rega, J. M. Millam, M. Klene, J. E. Knox, J. B. Cross, V. Bakken, C. Adamo, J. Jaramillo, R. Gomperts, R. E. Stratmann, O. Yazyev, A. J. Austin, R. Cammi, C. Pomelli, J. W. Ochterski, R. L. Martin, K. Morokuma, V. G. Zakrzewski, G. A. Voth, P. Salvador, J. J. Dannenberg, S. Dapprich, A. D. Daniels, Ö. Farkas, J. B. Foresman, J. V. Ortiz, J. Cioslowski and D. J. Fox, Gaussiano9 (Revision C.01), Gaussian Inc., Wallingford, CT, 2009.

28 J. J. P. Stewart, J. Mol. Model., 2007, 13, 1173-1213.

29 C. Peng, P. Ayala, H. B. Schlegel and M. J. Frisch, J. Comput. Chem., 1996, 17, 49-56.

30 A. Stegmüller, P. Rosenow and R. Tonner, Phys. Chem. Chem. Phys., 2014, 16, 17018-17029.

31 H. P. Hratchian and H. B. Schlegel, J. Chem. Theory Comput., 2005, 1, 61-69.

32 O. Sackur, Ann. Phys., 1911, 36, 958-980.

33 L.-O. Björketun, L. Hultman, I. P. Ivanov, Q. Wahab and J.-E. Sundgren, J. Cryst. Growth, 1997, 182, 379-388. 
34 Joint Committee on Powder Diffraction Standards, JCPDS, 38 A. Stegmüller and R. Tonner, Chem. Vap. Deposition, 2015, Swarthmore, PA, PDF card no. 00-056-0159.

21, 161-165.

35 Joint Committee on Powder Diffraction Standards, JCPDS, 39 C. D. Stinespring and J. C. Wormhoudt, J. Cryst. Growth, Swarthmore, PA, PDF card no. 00-029-1129. 1988, 87, 481-493.

36 O. Knotek, E. Lugscheider and C. W. Siry, Surf. Coat. 40 G. M. Petrov and J. L. Giuliani, J. Appl. Phys., 2001, 90, Technol., 1997, 91, 167-173. 619-636.

37 A. Stegmüller and R. Tonner, Inorg. Chem., 2015, 54, 41 W. Tsang and R. F. Hampson, J. Phys. Chem. Ref. Data, 1986, 6363-6372. 15, 1087-1279. 